\title{
KAJIAN FINANSIAL PENGEMBANGAN BIODIESEL \\ KEMIRI SUNAN (Reutealis trisperma (Blanco) Airy Shaw) PADA LAHAN TERSEDIA DI JAWA BARAT \\ (The Financial Analysis of Biodiesel Kemiri Sunan (Reutealis trisperma (Blanco) Airy Shaw) at the Available Lands on West Java)
}

\author{
Wening Sri Wulandari ${ }^{1}$, Dudung Darusman ${ }^{2}$, Cecep Kusmana ${ }^{2}$, Widiatmaka ${ }^{3}$ \\ ${ }^{1}$ Program Doktor, Program Studi Pengelolaan Sumberdaya Alam dan Lingkungan, \\ Institut Pertanian Bogor, Kampus IPB Baranangsiang, Bogor, Indonesia; \\ e-mail: weningwulandari@yahoo.com \\ ${ }^{2}$ Fakultas Kehutanan Institut Pertanian Bogor, Kampus IPB Darmaga, Bogor, Indonesia; \\ e-mail:ddarusman@yahoo.com, ckusmana@ymail.com. \\ ${ }^{3}$ Fakultas Pertanian Institut Pertanian Bogor, Kampus IPB Darmaga, Bogor, Indonesia; \\ e-mail: widiatmaka@yahoo.com
}

Diterima 10 Desember 2014 direvisi 22 Januari 2015 disetujui 12 Februari 2015

\begin{abstract}
One of potential vegetable materials in Indonesia as a source of biodiesel is kemiri sunan (Reutealis trisperma (Blanco) Airy Shaw). This study aims to analyze: financial feasibility of plantation; financial feasibility of biodieselprocessing, and the development of business unit. The research results show that kemiri sunan plantation is feasible on the area of 60 ba, a business period of 50 years. Feasibility values without loan are: NPV IDR 1,101,007,645; IRR 13.52\%; BCR 1.36; PBP 14.68 years, feasibility values with loan are: NPV IDR 160,351,357; IRR 13.52\%; BCR 1.08; PBP 22.55 years, sensitive to the decrease of selling price of dry seeds and productivity of the trees. The biodiesel processing business is feasible at the business period of 15 years, the production capacity of 202.75 Kl/year. Feasibility values without loan are: NPV IDR 512,549,740; IRR 27.27\%; BCR 1.04; PBP 4. 32 years, feasibility values with loan are: NPV IDR 303,310,940; IRR 27.27\%; BCR 1.03; PBP 4.94 years, sensitive to the rising costs of materials and a decrease in the selling price. If all available lands were cultivated, it will generate 2,365 business units and to produce biodiesel that meets $16.68 \%$ of the needs of West Java diesel oil.
\end{abstract}

Keywords: Feasibility, biodiesel, kemiri sunan (Reutealis trisperma (Blanco) Airy Shaw), available land.

\begin{abstract}
ABSTRAK
Salah satu bahan nabati potensial di Indonesia sebagai sumber biodiesel adalah kemiri sunan (Reutealis trisperma (Blanco) Airy Shaw). Penelitian bertujuan mengkaji: 1) kelayakan finansial penanaman kemiri sunan; 2) kelayakan finansial pengolahan biodiesel kemiri sunan; 3) pengembangan unit usaha pada lahan tersedia. Hasil penelitian menunjukkan bahwa penanaman kemiri sunan layak diusahakan pada luas 60 ha, umur usaha 50 tahun. Nilai kelayakan dengan dana sendiri: NPV Rp 1.101.007.645; IRR 13,52\%; BCR 1,36; PBP 14,68 tahun. Nilai kelayakan dengan dana pinjaman : NPV Rp 160.351.357; IRR 13,52\%; BCR 1,08; PBP 22,55 tahun. Pembangunan tanaman kemiri sunan sensitif terhadap penurunan harga jual biji kering dan penurunan produktivitas tanaman $\geq 28 \%$. Pengolahan biodiesel layak diusahakan pada umur usaha 15 tahun, kapasitas produksi 202,75 Kl/tahun. Nilai kelayakan dengan dana sendiri : NPV Rp 512.549.740; IRR 27,27\%; BCR 1,04; PBP 4,32 tahun. Nilai kelayakan dengan dana pinjaman: NPV Rp 303.310.940; IRR 27,27\%; BCR 1,03; PBP 4,94 tahun. Pengolahan biodiesel kemiri sunan sensitif terhadap kenaikan biaya bahan dan tenaga kerja penurunan harga biodiesel mencapai $\geq 6 \%$. Jika seluruh lahan tersedia ditanami akan berpeluang menghasilkan 2.365 unit usaha dan biodiesel yang memenuhi $16,68 \%$ kebutuhan solar Jawa Barat.
\end{abstract}

Kata kunci: Kelayakan, biodiesel, kemiri sunan (Reutealis trisperma (Blanco) Airy Shaw), lahan tersedia.

\section{PENDAHULUAN}

Seiring dengan meningkatnya kepedulian manusia terhadap kelestarian lingkungan dan perubahan iklim, upaya penggunaan bahan ramah lingkungan semakin meningkat. Begitu pula di bidang energi mulai dikembangkan energi terbarukan yang ramah lingkungan, di antaranya 
biodiesel yang bersumber dari bahan nabati. Menurut Diaz et al. (2012) biodiesel adalah rantai panjang alkil ester yang dapat menjadi sumber energi alternatif penting, karena merupakan biofuel yang terbarukan, biodegradable serta tidak beracun. Hal tersebut sejalan dengan Faria et al. (2013) bahwa biodiesel disarankan untuk bahan bakar alternatif fosil yang terbarukan karena dapat mengurangi toksisitas dan emisi gas buang.

Domac et al. (2005) menyatakan bahwa untuk keamanan energi dan manfaat lingkungan di negara berkembang, perlu didorong pengembangan bioenergi dan teknologi energi terbarukan lainnya. Industri biodiesel di Indonesia belum berkembang dengan baik meskipun Indonesia memiliki potensi sumber bioenergi yang melimpah. Salah satu bahan nabati penghasil biodiesel yang prospektif di Indonesia adalah kemiri sunan (Reutealis trisperma (Blanco) Airy Shaw). Biodiesel dari kemiri sunan memi-liki keunggulan dari sumber nabati lainnya, yaitu: a) memiliki kandungan minyak de-ngan rendemen kurang lebih 50\% (Vossen \& Umali, 2002); b) biodiesel yang dihasilkan cukup tinggi, dengan rendemen dari minyak kasar sebesar 88$92 \%$; c) tidak bersaing dengan pangan karena minyak kemiri sunan mengandung asam $\alpha$ eleostearat 50\% (Vossen \& Umali, 2002); d) dapat mencegah erosi dan kerusakan tanah; e) memiliki umur produksi yang panjang dan $\mathrm{f}$ ) dapat menjerap karbon dengan baik. Menurut Herman \& Pranowo (2011), biomassa tajuk kemiri sunan adalah 1,5-2,5 ton per pohon, setara dengan stok karbon yang terakumulasi dalam biomassa $0,5-1,0$ ton per pohon. Keunggulan tersebut menjadi salah satu faktor kunci dalam upaya pengembangan biodiesel kemiri sunan selain krieria finansial.

Pengembangan biodiesel perlu memperhatikan dua faktor yaitu: 1) ketersediaan dan kesinambungan bahan baku dan 2) ketersediaan teknologi pengolahan biodiesel. Ketersediaan dan kesinambungan bahan baku sangat penting untuk menjamin kelangsungan produksi. Hal ini harus didukung penanaman kemiri sunan dengan luasan yang dapat mencukupi kebutuhan bahan baku untuk pengolahan biodiesel. Penentuan lahan untuk penanaman kemiri sunan harus memperhatikan kesesuaian lahan agar dapat tumbuh dan berproduksi dengan baik. Hardjowigeno \& Widiatmaka (2007) mendefinisikan kesesuaian lahan yaitu kecocokan lahan untuk tipe penggunaan tertentu, baik jenis tanaman maupun tingkat pengelolaannya. Lebih lanjut Hardjowigeno dan Widiatmaka (2007) menyatakan bahwa informasi kesesuaian lahan dan potensi merupakan hal yang perlu diketahui sebelum merencanakan tataguna lahan. Supriadi et al. (2009) menyampaikan tanaman kemiri sunan tumbuh dan berproduksi dengan baik di Kabupaten Majalengka, Sumedang dan Garut, Jawa Barat. Kementerian Pertanian telah melepas varietas unggul kemiri sunan 1 dan kemiri sunan 2 sebagaimana Surat Keputusan Menteri Pertanian No. 4000/Kpts/SR.120/9/ 2011. Varietas unggul kemiri sunan 2 direkomendasikan untuk dikembangkan se-bagai tanaman penghasil biodiesel karena memiliki kandungan minyak yang lebih banyak yaitu 47,21$56,00 \%$. Teknologi budidaya kemiri sunan, mulai dari persemaian dan pembenihan sampai dengan pemeliharaan sudah dikuasai sebagaimana disampaikan oleh Herman et al. (2013). Teknologi pengolahan biodiesel kemiri sunan telah tersedia dan menghasilkan kualitas biodiesel yang memenuhi standar. Aunillah dan Pranowo (2012) menyatakan bahwa pembuatan biodiesel kemiri sunan dengan transesterifikasi dua tahap dapat menghasilkan kualitas biodiesel yang memenuhi se-mua kriteria SNI 1782:2012 (17 parameter), kecuali residu karbon belum memenuhi kriteria, namun dapat diatasi dengan proses pencucian yang lebih bersih.

Jika dukungan teknologi tersedia, untuk pengembangan biodiesel lebih lanjut diperlukan dukungan kepastian usaha sebagai bahan pertimbangan bagi para pelaku usaha dalam melakukan perencanaan investasi. Salah satu metode untuk memprediksi kepastian usaha adalah dengan informasi kelayakan finansial. Khotimah et al. (2002) menyatakan bahwa aspek finansial merupakan salah satu unsur kritis dalam formulasi proyek, sebagai informasi mengenai kemampuan proyek untuk berkembang dan mandiri secara finansial. Kelayakan finansial dinilai berdasarkan: 1) Net Pre-sent Value (NPV);2) Interest Rate of Return (IRR); 3) Net Benefit Cost Ratio (Net BCR) dan 4) Pay Back Period (PBP). Yang et al. (2012) menggunakan kriteria NPV, IRR dan PBP untuk menganalisis kelayakan ekonomi proyek energi terbarukan di China dengan beberapa skenario. Menurut Brent (2006), manfaat saat ini akan lebih dipilih karena manfaat di masa depan tidak ada kepastian untuk dapat menikmatinya. Untuk mendukung pengembangan biodiesel kemiri sunan diperlukan 
kajian finansial yang komprehensif hulu-hilir, yaitu kajian finansial penanaman kemiri sunan untuk penyiapan bahan baku dan kajian finansial pengolahan biodiesel kemiri sunan. Berdasarkan hal tersebut, maka penelitian ini bertujuan: 1) mengkaji kelayakan finansial penanaman kemiri sunan di Jawa Barat; 2) mengkaji kelayakan finansial pengolahan biodiesel kemiri sunan Jawa Barat dan 3) mengkaji pengembangan unit usaha berdasarkan lahan tersedia untuk penanaman kemiri sunan di Jawa Barat.

\section{METODE PENELITIAN}

\section{A. Tempat dan Waktu Penelitian}

Penelitian dilakukan di Bogor, Sukabumi dan Majalengka, Provinsi Jawa Barat. Pemilihan daerah studi didasarkan pada keberadaan pakar dan ketersediaan berbagai informasi terkait pengembangan biodiesel kemiri sunan. Penelitian dilaksanakan selama enam bulan (April - September 2014).

Tabel 1. Jenis dan sumber data yang digunakan dalam penelitian

Table 1. The types and sources of data used in the study

\begin{tabular}{|c|c|c|}
\hline Data (Data) & $\begin{array}{l}\text { Jenis data } \\
\text { (Data type) }\end{array}$ & Sumber Data (Data source) \\
\hline \multicolumn{3}{|l|}{$\begin{array}{l}\text { 1. Penanaman kemiri sunan (Planting of kemiri } \\
\text { sunan) }\end{array}$} \\
\hline $\begin{array}{l}\text { - Kebutuhan tenaga kerja dan bahan } \\
\text { pembuatan tanaman (Needs of labour and } \\
\text { material of planting }\end{array}$ & Sekunder & Dishutbun Majalengka \\
\hline $\begin{array}{l}\text { - Pemeliharaan tanaman (Plant } \\
\text { maintenance) }\end{array}$ & Sekunder & Herman, et al. (2013) \\
\hline $\begin{aligned} \text { - Produksi biji kering kemiri sunan } \\
\text { (Production of dry seedskemiri sunan) }\end{aligned}$ & Primer & (Herman, M., 24 Juni 2014, komunikasi pribadi) \\
\hline \multicolumn{3}{|l|}{$\begin{array}{l}\text { 2. Pengolahan biodiesel kemiri sunan } \\
\text { (Biodiesel processing of kemiri sunar) }\end{array}$} \\
\hline $\begin{array}{l}\text { - Peralatan dan pemeliharaan (Equipment } \\
\text { and maintenance) }\end{array}$ & Primer & (Pranowo, D., 5 April 2014, komunikasi pribadi) \\
\hline $\begin{array}{l}\text { - Kebutuhan listrik dan bahan } \\
\text { pengolahan biodiesel (Needs of electricity } \\
\text { and biodiesel processing materials) }\end{array}$ & Sekunder & Listyati (2009) \\
\hline \multicolumn{3}{|l|}{ 3. Harga (Price) } \\
\hline - Biodiesel, distribusi (Biodiesel, distribution) & Sekunder & $\begin{array}{l}\text { Keputusan Menteri ESDM No. } 2185 \text { K/12/MEM/ } \\
2014 \text { Keputusan Menteri ESDM No } 2187 \\
\text { K/12/MEM/ } 2014\end{array}$ \\
\hline - Listrik (Electricity) & Sekunder & $\begin{array}{l}\text { Peraturan Menteri Energi dan Sumber Daya Mineral } \\
\text { No. } 09 \text { tahun } 2014 \text { tentang Tarif Tenaga Listrik yang } \\
\text { Disediakan oleh PT PLN (Persero) }\end{array}$ \\
\hline - Air (Water) & Sekunder & PDAM \\
\hline - Bahan kimia (Chemicals) & Primer & Toko sarana pertanian dan bahan kimia, Bogor \\
\hline - Bungkil (Oilcake) & Sekunder & Balittri \\
\hline $\begin{array}{l}\text { - Gliserol kotor (Glycerol which has not been } \\
\text { purified) }\end{array}$ & Primer & (Pranowo, D., 5 April 2014, komunikasi pribadi) \\
\hline - Upah (Cost of laboui) & Sekunder & Kementerian Keuangan; Pustekolah \\
\hline \multicolumn{3}{|l|}{ 4. Kesesuaian lahan (Land suitability) } \\
\hline $\begin{array}{l}\text { - Luas lahan tersedia (Area of available } \\
\text { lands) }\end{array}$ & Sekunder & Wulandari et al. (2014) \\
\hline - Peta lahan tersedia (Map of available lands) & Sekunder & Wulandari et al. (2014) \\
\hline $\begin{array}{l}\text { - Volume distribusi solar Jawa Barat } 2012 \\
\text { (Volume of diesel fuel distribution in West } \\
\text { Jawa 2012) }\end{array}$ & Sekunder & Dinas ESDM Jawa Barat \\
\hline
\end{tabular}




\section{B. Jenis dan Sumber Data}

Data yang digunakan untuk analisis adalah data primer dan data sekunder. Jenis dan sumber data sebagaimana Tabel 1.

\section{Asumsi}

Asumsi yang digunakan dalam analisis finansial adalah sebagai berikut:

1. Asumsi yang digunakan dalam analisis pembangunan tanaman kemiri sunan:

a. Harga yang digunakan adalah harga tahun 2014.

b. Luas lahan adalah 60 ha sesuai dengan kebutuhan biji untuk pengolahan biodiesel.

c. Kemiri sunan ditanam di lahan sendiri atau lahan pemerintah.

d. Masa analisis adalah 50 tahun.

e. Jumlah pohon per ha sebanyak 156 pohon.

f. Kemiri sunan mulai berproduksi pada umur 4 tahun sebanyak 12,5 $\mathrm{kg}$ biji kering per pohon, umur lima tahun $25 \mathrm{~kg}$ biji kering per pohon, umur enam tahun $50 \mathrm{~kg}$ biji kering per pohon, umur tujuh tahun $75 \mathrm{~kg}$ biji kering per pohon. Mulai umur delapan tahun dan seterusnya, produksi biji kering per pohon adalah $100 \mathrm{~kg}$.

g. Harga biji kering kemiri sunan Rp $750 / \mathrm{kg}$, tetap selama masa analisis.

h. Semua pohon berproduksi.

2. Asumsi yang digunakan dalam analisis pengolahan biodiesel:

a. Harga yang digunakan adalah harga tahun 2014.

b. Kapasitas alat sekali proses adalah 400 liter minyak kasar kemiri sunan (MKKS).

c. Satu hari dilakukan dua kali proses.

d. Hari efektif adalah 24 hari per bulan dan 12 bulan per tahun.

e. Jumlah biji kering kemiri sunan yang digunakan untuk satu kali proses adalah 1.600 kg dengan harga Rp 775/ kg.

f. Masa analisis adalah 15 tahun sesuai masa pakai alat.

g. Rendemen biji kering menjadi kernel 50\%, rendemen kernel menjadi MKKS 50\% dan rendemen MKKS menjadi biodiesel 88\%.

h. Banyaknya bungkil adalah 50\% dari kernel dan gliserol sebanyak $12 \%$ dari MKKS.

i. Bahan baku dan bahan penunjang tersedia sesuai kebutuhan. j. Alat beroperasi dengan lancar.

k. Harga biodiesel dan bahan tetap selama masa analisis. Harga jual biodiesel sesuai harga jual yang ditetapkan pemerintah setelah dikurangi biaya distribusi yaitu $R p$ 8.480,37 / liter.

\section{Tahapan Analisis}

1. Mengidentifikasi kegiatan. Identifikasi dilakukan pada kegiatan pembuatan tanaman kemiri sunan dan pengolahan biodiesel untuk mengetahui komponen biaya yang harus dikeluarkan.

2. Mengidentifikasi biaya satuan kegiatan dan harga produk. Biaya satuan kegiatan digunakan sebagai dasar perhitungan biaya yang dibutuhkan dalam pelaksanaan kegiatan, sedangkan harga produk yang dihasilkan digunakan untuk menghitung pendapatan.

3. Menghitung biaya dan pendapatan. Biaya dan pendapatan dihitung dengan mengacu pada asumsi yang digunakan dalam analisis.

4. Melakukan analisis finansial. Analisis finansial dilakukan berdasarkan (Sanusi, 2000):

a. Net Present Value (NPV)

$\mathrm{NPV}=$ Present value dari Benefit Present value dari Cost

b. Interest Rate of Return (IRR)

$$
\begin{aligned}
& \text { IRR i' } \frac{N P V '}{N P V^{\prime} N P V^{\prime \prime}}\left(i^{\prime \prime} i^{\prime}\right) \\
& i^{\prime}=\text { discount rate pada NPV' } \\
& \mathrm{i}^{\prime}=\text { discount rate pada NPV" } \\
& \mathrm{i}^{\prime \prime}>\mathrm{i} \text { ' }
\end{aligned}
$$

c. NetBenefit CostRatio (BCR)

$$
N \text { etBCR }=\frac{\Sigma \text { Present value net benefit }}{\Sigma \text { Present value net cost }}=\frac{\text { Net B }}{\text { Net C }}
$$

\section{d. Pay Back Period (PBP)}

5. Melakukan analisis sensitivitas. Analisis sensitivitas dilakukan untuk mengetahui penyesuaian yang dapat dilakukan jika terjadi perubahan harga bahan dan harga jual produk.

6. Menghitung jumlah unit usaha, jumlah biodiesel dan persen kontribusi biodiesel terhadap kebutuhan solar:

a. Jumlah unit usaha

$$
\underset{\text { nit usaha }}{\text { Jumlah }}=\frac{\text { luas lahan tersedia (ha) }}{\text { luas unit usaha (ha) }}
$$


b. Produksi biodiesel per ha

$\begin{gathered}\text { Produksi } \\ \text { biodiesel } \\ \text { perha (l) }\end{gathered}=\begin{gathered}\text { jumlah biji kering per ha x } \\ \text { rendemen } \text { MKKS x } \mathrm{x} \\ \text { rendemen biodiesel }\end{gathered}$

c. Produksi biodiesel pada lahan tersedia

Produksi

biodiesel $=$ produksi biodiesel per ha

pada lahan $\quad$ x luas lahan

tersedia (l)

d. Kontribusi biodiesel terhadap kebutuh-an solar Jawa Barat

\begin{tabular}{|c|c|}
\hline & $\begin{array}{c}\text { produksi biodiesel pada } \\
\text { lahan tersedia }\end{array}$ \\
\hline usi $(\%)$ & kebutuhan solar Jawa Bara \\
\hline
\end{tabular}

\section{HASIL DAN PEMBAHASAN}

\section{A. Kelayakan Finansial Pembangunan Tanaman Kemiri Sunan}

Luas unit usaha penanaman kemiri sunan adalah 60 ha. Untuk menjamin kepastian ketersediaan bahan baku untuk industri pengolah biodieselnya, luas unit usaha ditetapkan dalam skala teknis, disesuaikan dengan kapasitas mesin pengolah biodiesel. Kapasitas mesin pengolah biodiesel adalah 400 liter MKKS sekali proses. Dalam sehari dilaksanakan dua kali proses yang berarti membutuhkan 800 liter MKKS, yang diperoleh dari $3.200 \mathrm{~kg}$ biji kering. Dengan perhitungan satu bulan 24 hari efektif maka dalam satu tahun dibutuhkan $921.600 \mathrm{~kg}$ biji kering. Jumlah pohon kemiri sunan per ha adalah 156 pohon dengan rata-rata produksi pohon kemiri sunan adalah 100 kg biji kering/ pohon. Dengan demikian, kebutuhan biji kering dapat dipenuhi dengan penanaman kemiri sunan seluas 60 ha.

Pembangunan tanaman kemiri sunan terdiri dari kegiatan pembuatan tanaman, pemeliharaan dan pemanenan. Biaya penanaman mencakup biaya bibit, ajir bambu, pupuk, pestisida, biaya tenaga kerja untuk pembersihan lahan, penyiapan lubang tanam, penanaman dan pengajiran. Biaya pemeliharaan mencakup biaya pembelian pupuk, pestisida dan biaya tenaga kerja.

Herman et al. (2013) membedakan pemeliharaan tanaman kemiri sunan menjadi pemeliharaan tanaman belum menghasilkan (TBM) dan pemeliharaan tanaman menghasilkan (TM). Komponen yang membedakan besarnya biaya pemeliharaan adalah jumlah pupuk dan jenis pembasmi OPT yang digunakan. Pranowo (2009) memberikan acuan takaran pupuk per pohon pada berbagai tingkatan umur tanaman kemiri sunan. Biaya pemeliharaan tanaman dikeluarkan pada tahun pertama. Biaya pada tahun ke-2 sampai dengan tahun ke-4 adalah biaya pemeliharaan TBM yaitu pada saat tanaman berumur tiga tahun. Kemiri sunan mulai menghasilkan biji pada tanaman berumur empat tahun, di mana memerlukan intensitas pemeliharaan dan biaya yang lebih besar dibandingkan pemeliharaan pada tanaman tahun sebelumnya. Biaya pemanenan dikeluarkan mulai tahun ke-4 yang meliputi biaya panen dan biaya jemur. Buah yang dipanen adalah buah yang telah matang secara fisiologi yang biasanya akan jatuh secara alami. Oleh karena itu, pemanenan kemiri sunan tidak menggunakan alat khusus ataupun tenaga kerja yang banyak karena pemanenan dilakukan dengan memungut buah yang telah jatuh dan selanjutnya dikeringkan sampai kadar air tertentu. Herman et al. (2013) menyebutkan bahwa kemiri sunan dikeringkan sampai kadar air $<10 \%$. Biaya panen dan jemur dinyatakan dalam satuan per kilogram, sehingga besarnya biaya jemur mengikuti jumlah biji kering yang dipanen. Hasil identifikasi kegiatan dan biaya satuan untuk penanaman kemiri sunan per ha secara lengkap diuraikan pada Tabel 2.

Pendapatan dari pembangunan tanaman kemiri sunan adalah bersumber dari penjualan biji kering kemiri sunan. Besarnya pendapatan bervariasi, tergantung dari jumlah produksi biji kemiri sunan. Kemiri sunan mulai berbuah pada umur empat tahun dengan produksi awal berkisar 12,5 kg biji kering/pohon. Produksi semakin bertambah sampai dengan umur delapan tahun dan seterusnya rata-rata sebanyak $100 \mathrm{~kg}$ biji kering/pohon. Dengan harga jual biji kering kemiri sunan Rp $750 / \mathrm{kg}$, maka pendapatan penjualan biji kering yang diperoleh mulai tahun ke-5, 6, 7, 8 dan 9 berturut-turut adalah Rp 87.750.000, Rp 175.500.000, Rp 351.000.000, Rp 526.500.000, Rp 702.000.000. Pendapatan tahun ke-10 dan seterusnya sama dengan tahun ke-9 karena jumlah biji kering kemiri sunan yang dihasilkan sama. 
Tabel 2. Komponen biaya pembangunan tanaman kemiri sunan

Table 2. The cost components of kemiri sunan plantation development

\begin{tabular}{|c|c|c|}
\hline Jenis biaya (Cost type) & Satuan (unit) & $\begin{array}{l}\text { Biaya satuan (Unit cost) } \\
(\mathrm{Rp})\end{array}$ \\
\hline Biaya pembuatan tanaman (Cost of planting) & ha & 7.643 .330 \\
\hline $\begin{array}{l}\text { Biaya pemeliharaan TBM umur } 1 \text { dan } 2 \text { tahun } \\
\text { (Cost of immature plant maintenance at age } 1 \text { and } 2 \text { years) }\end{array}$ & ha & 2.597 .220 \\
\hline $\begin{array}{l}\text { Biaya pemeliharaan TBM umur } 3 \text { tahun } \\
\text { (Cost of immature plant maintenance at age } 3 \text { years) }\end{array}$ & ha & 2.227 .680 \\
\hline $\begin{array}{l}\text { Biaya pemeliharaan TM umur } 4 \text { tahun } \\
\text { (Cost of productive plant maintenance at age } 4 \text { years) }\end{array}$ & ha & 2.227 .680 \\
\hline $\begin{array}{l}\text { Biaya pemeliharaan TM umur } 5 \text { tahun } \\
\text { (Cost of productive plant maintenance at age } 4 \text { years) }\end{array}$ & ha & 2.315 .040 \\
\hline $\begin{array}{l}\text { Biaya pemeliharaan TM umur 6-50 tahun } \\
\text { (Cost of productive plantmaintenance at age 6-50 years) }\end{array}$ & ha & 2.489 .760 \\
\hline Biaya panen dan jemur (Cost of harvesting and drying) & $\mathrm{kg}$ & 110 \\
\hline
\end{tabular}

Sumber (Source): Sumber data, Tabel 1.

Tabel 3. Nilai kelayakan pembangunan tanaman kemiri sunan

Table 3. The feasibility of kemiri sunan plantation development

\begin{tabular}{|c|c|c|}
\hline \multirow{2}{*}{ Kriteria kelayakan (Criteria of feasibilit) } & \multicolumn{2}{|c|}{ Nilai (Value) } \\
\hline & Tingkat diskon (Discount rate) 7,5\% & Tingkat diskon (Discount rate) $12 \%$ \\
\hline NPV (Rp) & 1.101.007.645 & 160.351 .357 \\
\hline IRR $(\%)$ & 13,52 & 13,52 \\
\hline BCR & 1,36 & 1,08 \\
\hline PBP (tahun) (year) & 14,68 & 22,55 \\
\hline
\end{tabular}

Analisis finansial dilakukan pada dua nilai discount rate yaitu $7,5 \%$ sesuai standar Bank Indonesia untuk analisis menggunakan dana sendiri dan $12 \%$ untuk analisis menggunakan dana pinjaman bank. Berdasarkan hasil analisis finansial terhadap pembangunan tanaman kemiri sunan seluas 60 ha dengan umur analisis selama 50 tahun diperoleh nilai NPV, IRR, BCR dan PBP seperti ditunjukkan Tabel 3.

Berdasarkan Tabel 3, nilai NPV menunjukkan nilai positif yang berarti pembangunan tanaman kemiri sunan layak untuk dilaksanakan. Yang et al. (2012) menyatakan bahwa NPV adalah nilai saat ini dari arus kas masa mendatang. Dalam analisis ini, nilai NPV yang akan diterima adalah Rp 1.101.007.645 jika menggunakan dana sendiri. Analisis juga dilakukan menggunakan sumber modal usaha berasal dari pinjaman, dengan pertimbangan bahwa petani atau pelaku usaha pada umumnya tidak memiliki modal usaha dan memerlukan bahan atau peralatan yang tidak bisa diusahakan dengan sumberdayanya sendiri. NPV yang akan diterima adalah Rp 160.351.357. Besarnya pinjaman ditentukan sesuai dengan biaya yang dibutuhkan untuk operasional usaha dan pembayaran bunga selama net benefit masih negatif yaitu sebesar $\mathrm{Rp}$ 1.449.048.088. Sesuai dengan program subsidi bunga yang dikembangkan pemerintah untuk pengembangan energi nabati, petani mendapatkan grace period untuk hanya membayarkan bunga selama belum ada pendapatan. Dalam analsis ini, grace period selama enam tahun dengan bunga $7 \%$. Petani dapat memperoleh pendapatan antara dengan menanam tanaman bawah karena kemiri sunan ditanam dengan jarak tanam yang lebar yaitu $8 \mathrm{~m}$ x $8 \mathrm{~m}$ sehingga memiliki ruang bawah yang cukup luas. Sebelum tajuk menutup, ruang ini dapat dimanfaatkan untuk menanam tanaman musiman atau tanaman berdaur pendek.

Untuk jaminan kepastian usaha selanjutnya perlu dilakukan analisis sensitivitas agar dapat diketahui kelayakan usaha jika terjadi perubahan 
terhadap biaya dari komponen kegiatan. Pada analisis sensitivitas, dilakukan simulasi terhadap penurunan harga biji kering dan penurunan produktivitas tanaman.

Jika melihat kecenderungan kebutuhan solar yang semakin meningkat dan kelebihan kemiri sunan sebagai sumber biodiesel, kecil kemungkinan terjadi penurunan harga kemiri sunan. Namun demikian, produksi pada masa panen yang bersamaan perlu diantisipasi karena berpotensi menjadi salah satu penyebab penurunan harga biji kering kemiri sunan. Selain itu penurunan kualitas biji kering yang disebabkan ketidaktepatan penanganan bisa menyebabkan penurunan harga.

Penurunan produktivitas dapat terjadi jika pohon kemiri sunan mendapat serangan hama atau penyakit yang dapat menyebabkan gagal berbuah. Herman et al. (2013) menyebutkan bahwa tungau, moluska dan hama penggerek batang merupakan hama yang menyerang tanaman kemiri sunan. Biji atau buah kemiri sunan biasanya diserang oleh larva Docus sp. dan kumbang penggerek buah. Selain hama, terdapat pula penyakit yang menyerang kemiri sunan yang disebabkan adanya jamur akar putih dan jamur akar coklat, hawar daun cendawan, penyakit antraknosa dan penyakit gugur buah muda.

Perubahan harga biji kering dan penurunan produktivitas memberikan pengaruh yang sama. Jika harga biji kering dan produktivitas tanaman turun sampai dengan $28 \%$ atau lebih maka menjadi tidak layak karena nilai NPV negatif sebesar Rp (14.468.609). Jika penurunan harga dan produktivitas di bawah $28 \%$ maka pembangunan tanaman kemiri sunan masih layak, dengan nilai NPV positif sebesar Rp 25.369.829. Faktor harga maupun produksi biji kering memiliki peranan penting dalam kelayakan pembangunan tanaman kemiri sunan karena biji kering merupakan sumber tunggal pendapatan. Upaya mempertahankan kualitas biji dapat dilakukan melalui pemeliharaan tanaman secara intensif sesuai ketentuan budidaya tanaman agar dapat mengurangi potensi serangan hama dan penyakit serta penanganan biji pasca panen dengan baik.

\section{B. Kelayakan Finansial Pengolahan Biodiesel Kemiri Sunan}

Dalam pengolahan biodiesel kemiri sunan diperlukan biaya untuk pengadaan alat, biaya pemeliharaan dan biaya operasional. Alat pengolahan kemiri sunan terdiri dari reaktor, pengupas, pengepres dan penyaring. Balai Penelitian Tanaman Industri dan Penyegar (Balittri) telah mengembangkan alat dan reaktor biodiesel. Pranowo et al. (2013) menyebutkan bahwa reaktor biodiesel yang dikembangkan merupakan reaktor multifungsi yang memiliki beberapa kelebihan yaitu kondensor ganda, dapat dilakukan pengaturan kecepatan pengadukan, suhu maksimal proses mencapai $120^{\circ} \mathrm{C}$, le-bih sedikit menggunakan katalis, empat sampai enam jam sekali proses, dapat mengolah minyak dari semua jenis minyak nabati dengan berbagai tingkatan asam lemak bebas dan menghasilkan rendemen 87-92\%. Pemeliharaan peralatan dilakukan untuk penggantian spare part dan pembelian pelumas.

Biaya operasional mencakup komponen: 1) biaya listrik untuk proses pengupasan biji, pengepresan biji, transesterifikasi tahap 1-2, pencucian tahap 1-3, pengeringan dan recovery methanol; 2) biaya bahan yang mencakup biji kering kemiri sunan, methanol, $\mathrm{KOH}$ dan air bersih serta 3) biaya upah operator. Kebutuhan listrik dan beberapa bahan untuk proses biodiesel menggunakan dasar hasil penelitian Listyati (2009) yang disesuaikan dengan kapasitas produksi sesuai unit penelitian. Hasil identifikasi biaya pengolahan biodiesel kemiri sunan selama satu tahun ditunjukkan dalam Tabel 4.

Tabel 4. Biaya pengolahan biodiesel kemiri sunan

Table 4. The cost of biodiesel kemiri sunan processing

\begin{tabular}{lrr}
\hline \multicolumn{1}{c}{ Jenis biaya (Cost type) } & Satuan (Unit) & Biaya (Cost) (Rp) \\
\hline Mesin biodiesel kapasitas 400 liter minyak kasar kemiri sunan (Machine of & set & 374.000 .000 \\
biodiesel processing with capacity 400 D & & 1.800 .000 \\
Pemeliharaan (sparepart dan pelumas) (Maintenance) & tahun & 105.261 .470 \\
Listrik (Electricity) & tahun & 1.224 .737 .280 \\
Bahan (Materials) & tahun & 86.400 .000 \\
Tenaga kerja (Labour) & tahun \\
\hline
\end{tabular}


Investasi pembelian alat dilakukan satu kali pada tahun pertama, sedangkan biaya pengolahan biodiesel per tahun relatif tetap. Pengolahan biodiesel kemiri sunan menghasilkan produk utama berupa biodiesel. Harga biodiesel mengacu Kementerian ESDM tahun 2014 dikurangi dengan biaya distribusi. Untuk menghasilkan satu liter biodiesel kemiri sunan diperlukan 4,55 kg biji kering kemiri sunan. Dengan harga biji kering kemiri sunan Rp 775/kg maka biaya bahan baku per liter biodiesel adalah Rp 3.526,25.

Proses produksi biodiesel menghasilkan produk samping berupa gliserol (Hazegawa et al., 2014). Gliserol yang dihasilkan dari pengolahan biodiesel kemiri sunan adalah sebesar $12 \%$ dari MKKS (Wahyudi et al., 2009). Heryana et al. (2009) menyatakan bahwa limbah pengepresan minyak kemiri sunan menghasilkan bungkil berupa padatan atau ampas berwarna kuning, tawar dan tidak berbau. Bungkil kemiri sunan merupakan bahan dasar untuk pembuatan pupuk organik. Bungkil yang dihasilkan dari proses pengolahan biodiesel adalah sebesar $50 \%$ dari biji yang diolah. Methanol yang dipergunakan dalam proses pengolahan biodiesel masih tersisa pada akhir proses, sebesar kurang lebih 60\% yang bisa di-recovery dan dipisahkan serta dapat digunakan kembali dalam proses pengolahan biodiesel. Pendapatan pengolahan biodiesel kemiri sunan selama satu tahun sesuai dengan asumsi yang dipergunakan ditunjukkan pada Tabel 5.
Pendapatan pada Tabel 5 tersebut selanjutnya dipotong pajak sesuai dengan ketentuan UndangUndang No. 17 tahun 2000. Berdasarkan komponen biaya dan pendapatan, dilakukan analisis kelayakan pengolahan biodiesel kemiri sunan mengikuti asumsi yang ditetapkan. Seperti halnya analisis kelayakan pembangunan tanaman, analisis kelayakan pengolahan biodiesel kemiri sunan digunakan 2 nilai discount rate 7,5\% dan 12\%. Nilai kelayakan investasi pengolahan biodiesel kemiri sunan ditunjukkan pada Tabel 6.

Berdasarkan nilai kelayakan pada Tabel 6 maka pengolahan biodiesel kemiri sunan layak untuk diusahakan. Untuk usaha dengan pinjaman bank maka besarnya pinjaman adalah Rp 374.000.000 yang dipinjam pada tahun ke- 0 , untuk tahap persiapan berupa pembelian alat. Pada usaha pengolahan biodiesel, pelaku usaha sudah memperoleh pendapatan mulai tahun ke-1. Untuk mengantisipasi ketidakpastian atau kekurangtepatan dalam proyeksi, maka dilakukan analisis sensitivitas terhadap penurunan harga biodiesel dan kenaikan biaya bahan.

Komponen terbesar yang secara rutin dikeluarkan dalam pengolahan biodiesel adalah pembelian bahan dan tenaga kerja. Bahan berupa biji kemiri sunan dan bahan pembantu berupa katalis memiliki kemungkinan mengalami kenaikan harga sesuai fluktuasi harga pasar. Begitu pula dengan biaya tenaga kerja, memiliki kecenderungan penyesuaian mengikuti perkembangan

Tabel 5. Pendapatan pengolahan biodiesel kemiri sunan per tahun

Table 5. The income from kemiri sunan biodiesel processing for each year

\begin{tabular}{lcrr}
\hline \multicolumn{1}{c}{ Jenis pendapatan (Income type) } & Satuan (Unit) & Harga (Price) (Rp) & $\begin{array}{r}\text { Pendapatan per tahun } \\
\text { (Income/year) (Rp) }\end{array}$ \\
\hline Biodiesel (Biodiese) & liter & 8.480 & 1.719 .411 .980 \\
Bungkil (Oilcake) & $\mathrm{kg}$ & 370 & 85.939 .200 \\
Gliserol kotor (Glycerol which bas not been purified) & liter & 3.700 & 102.297 .600 \\
\hline
\end{tabular}

Tabel 6. Nilai kelayakan pengolahan biodiesel kemiri sunan

Table 6. The feasibility of biodiesel processing from kemiri sunan

\begin{tabular}{|c|c|c|}
\hline \multirow{2}{*}{ Kriteria kelayakan (Criteria of feasibility) } & \multicolumn{2}{|c|}{ Nilai (Value) } \\
\hline & Tingkat diskon (Discount rate) 7,5\% & Tingkat diskon (Discount rate) 12\% \\
\hline NPV (Rp) & 512.549 .740 & 303.310 .940 \\
\hline $\operatorname{IRR}(\%)$ & 27,27 & 27,27 \\
\hline $\mathrm{BCR}$ & 1,04 & 1,03 \\
\hline PBP (tahun) (year) & 4,32 & 4,94 \\
\hline
\end{tabular}


standar upah regional. Harga biodiesel dihitung dengan Harga Indeks Pasar Bahan Bakar Nabati (HIP BBN) berdasarkan Mean of Platts Singapore (MOPS). Tahun 2014 melalui Keputusan Menteri ESDM No. 2185 tahun 2014, harga biodiesel adalah sebesar USD 776,1 per Kl. Namun demikian, karena dasar perhitungannya berlandaskan harga publikasi MOPS biosolar, masih terdapat potensi penurunan maupun kenaikan karena harga publikasi MOPS sangat fluktuatif yang dipengaruhi perkembangan harga bahan baku tanaman untuk biosolar, misalnya kedelai, kelapa sawit ataupun tanaman lain.

Hasil analisis sensitivitas atas perubahan tersebut menunjukkan bahwa kenaikan biaya bahan menyebabkan pengolahan biodiesel kemiri sunan tidak layak jika kenaikan biaya bahan mencapai 6\% atau lebih, dengan NPV negatif sebesar Rp (90.849.480). Penurunan harga biodiesel menyebabkan pengolahan biodiesel kemiri sunan tidak layak jika penurunan harga mencapai $6 \%$ atau lebih dengan NPV negatif sebesar Rp (80.429.910). Penurunan biaya bahan dan penurunan harga biodiesel sebesar 5\%, pengolahan biodiesel masih layak untuk diusahakan.

\section{Kajian Pengembangan Unit Usaha Berdasarkan Lahan Tersedia untuk Penanaman Kemiri Sunan di Jawa Barat}

Wulandari et al. (2014) melakukan analisis lahan tersedia di Jawa Barat dengan mengintegrasikan kesesuaian lahan dengan penggunaan lahan dan pola ruang. Hasil penelitian menunjukkan bahwa lahan tersedia untuk penanaman kemiri sunan di Jawa Barat seluas 141.955, 56 ha terdiri dari lahan tersedia 1 (19.582,74 ha), lahan tersedia 2 (103.974,62 ha) dan lahan tersedia 3 (18.398,20 ha). Lahan tersedia 1 adalah lahan yang sangat sesuai untuk penanaman kemiri sunan, lahan tersedia 2 adalah lahan yang cukup sesuai, dan lahan tersedia 3 adalah lahan yang sesuai marginal. Luas lahan tersedia tersebar pada 17 kabupaten di Provinsi Jawa Barat. Lahan tersedia berupa kebun campuran, semak belukar, tanah terbuka dan tegalan yang berada pada areal pemanfaatan hutan, areal rawan bencana dan pedesaan. Peta lahan tersedia untuk penanaman kemiri sunan di Jawa Barat ditunjukkan pada Gambar 1.

Jumlah unit usaha, jumlah biodiesel dan kontribusi biodiesel terhadap kebutuhan solar Jawa Barat dihitung dengan asumsi produktivitas pohon

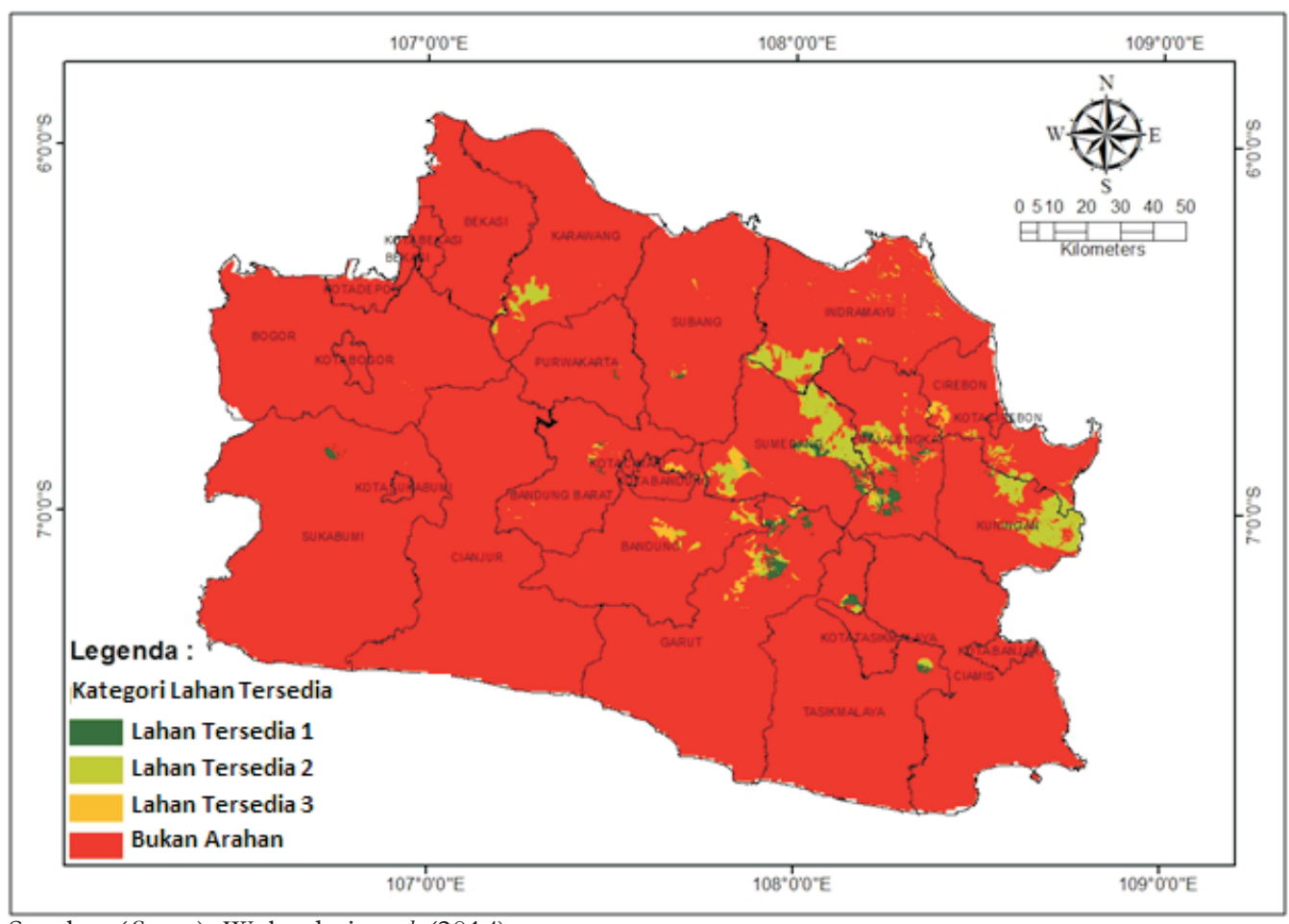

Sumber (Source): Wulandari et al. (2014).

Gambar 1. Peta lahan tersedia kemiri sunan di Jawa Barat.

Figure 1. Kemiri sunan land availability map in West Java. 
Tabel 7. Produksi biji kering dan biodiesel kemiri sunan dari lahan tersedia di Jawa Barat Table 7. Production of dry seeds and biodiesel kemiri sunan from available lands in West Java

\begin{tabular}{|c|c|c|c|c|c|c|c|}
\hline \multirow{2}{*}{$\begin{array}{l}\text { Kategori } \\
\text { lahan } \\
\text { tersedia } \\
\text { (Category of } \\
\text { available land) }\end{array}$} & \multirow{2}{*}{$\begin{array}{l}\text { Luas lahan } \\
\text { tersedia } \\
\text { (Area of } \\
\text { available land) } \\
\text { (ha) }\end{array}$} & \multirow{2}{*}{$\begin{array}{c}\text { Jumlah unit } \\
\text { penanaman/ } \\
\text { pengolahan } \\
\text { (Amount of } \\
\text { plantation units/ } \\
\text { processing) }\end{array}$} & \multicolumn{2}{|c|}{$\begin{array}{l}\text { Produksi biji kering } \\
\text { kemiri sunan } \\
\text { (Production of } d r y \text { seds } \\
\text { kemiri sunan })(\mathrm{kg}) \\
\end{array}$} & \multicolumn{2}{|c|}{$\begin{array}{c}\text { Produksi biodiesel } \\
\text { (Production of bodiesel) (Kl) }\end{array}$} & \multirow{2}{*}{$\begin{array}{c}\text { Kontribusi } \\
\text { biodiesel } \\
\text { terhadap } \\
\text { kebutuhan solar } \\
\text { Jawa Barat* } \\
\text { (Biodiesel } \\
\text { contribution to the } \\
\text { needs of West Java } \\
\text { diesel oil) (\%) }\end{array}$} \\
\hline & & & $\begin{array}{l}\text { per pohon } \\
\text { (for each } \\
\text { plant) }\end{array}$ & $\begin{array}{l}\text { per ha } \\
\text { (for each } \\
\text { ba) }\end{array}$ & $\begin{array}{l}\text { per ha } \\
\text { (for each } \\
\text { ba) }\end{array}$ & $\begin{array}{l}\text { total } \\
\text { (total) }\end{array}$ & \\
\hline $\begin{array}{l}\text { Lahan } \\
\text { tersedia } 1\end{array}$ & $19.582,74$ & 326 & 90 & 14.040 & 3,089 & $60.487,17$ & 2,90 \\
\hline $\begin{array}{l}\text { Lahan } \\
\text { tersedia } 2\end{array}$ & $103.974,62$ & 1732 & 70 & 10.920 & 2,402 & $249.788,63$ & 11,96 \\
\hline $\begin{array}{l}\text { Lahan } \\
\text { tersedia } 3 \\
\end{array}$ & $18.398,20$ & 307 & 50 & 9.360 & 2,059 & $37.885,57$ & 1,81 \\
\hline Total & $141.955,56$ & 2365 & & & & $348.161,37$ & 16,68 \\
\hline
\end{tabular}

Sumber (Source): Dinas ESDM Jawa Barat (2014).

Keterangan (Remark): * Kebutuhan solar didekati dengan volume distribusi solar Jawa Barat 2012 sebesar 2.087.702,24 kilo liter (kl).

kemiri sunan berbeda-beda sesuai dengan kategori lahan tersedia. Produktivitas pohon kemiri sunan pada kategori lahan tersedia 1, lahan tersedia 2 dan lahan tersedia 3 diasumsikan berturut-turut adalah $90 \%, 70 \%, 50 \%$ terhadap rata-rata produksi stabil kemiri sunan yaitu $100 \mathrm{~kg}$ per pohon per tahun. Hasil perhitungan secara lengkap ditunjukkan pada Tabel 7.

Berdasarkan Tabel 7 dapat diketahui unit usaha penanaman maupun pengolahan biodiesel yang dapat dikembangkan masing-masing adalah sebesar 2.365 unit. Pengembangan untit usaha ini disarankan untuk dikembangkan secara berpasangan agar terdapat kepastian pemasok bahan baku dan industri pengolahnya. Pengembangan unit usaha pada semua lahan tersedia berpotensi menghasilkan biodiesel sebesar 348.161,37 $\mathrm{Kl}$ atau berperan sebesar $16,68 \%$ dalam pemenuhan kebutuhan solar Jawa Barat. Pendekatan unit usaha skala kecil sesuai dengan luasan unit analisis yaitu 60 ha dan kapasitas produksi 202,75 Kl biodiesel per tahun merupakan strategi untuk memberikan kemudahan dan kesempatan usaha yang lebih merata bagi masyarakat. Abdulraheem et al. (2012) menyatakan bahwa usaha kecil di seluruh dunia merupakan dasar pembangunan ekonomi.

\section{KESIMPULAN DAN SARAN}

\section{A. Kesimpulan}

Pembangunan tanaman kemiri sunan layak diusahakan dengan luasan 60 ha, umur usaha 50 tahun, dengan dana sendiri maupun dana pinjaman. Nilai kelayakan dengan dana sendiri adalah: 1) NPV Rp 1.101.007.645; 2) IRR 13,52\%; 3) BCR 1,36 dan 4) PBP 14,68 tahun. Nilai kelayakan dengan dana pinjaman adalah: 1) NPV Rp 160.351.357; 2) IRR 13,52\%; 3) BCR 1,08 dan 4) PBP 22,55 tahun. Pembangunan tanaman kemiri sunan sensitif terhadap penurunan harga jual biji kering kemiri sunan dan penurunan produktivitas tanaman se-besar 28\% atau lebih. Perubahan pada kisaran persentase tersebut menyebabkan pembangunan tanaman kemiri sunan tidak layak untuk diusahakan.

Pengolahan biodiesel kemiri sunan layak diusahakan dengan umur usaha 15 tahun, kapasitas produksi 202,75 Kl per tahun, dengan dana sendiri maupun pinjaman. Nilai kelayakan dengan dana sendiri adalah: 1) NPV Rp 512.549.740; 2) IRR $27,27 \%$; 3) BCR 1,04 dan 4) PBP 4,32 tahun. Nilai kelayakan dengan dana pinjaman adalah: 1) NPV Rp 303.310.940; 2) IRR 27,27\%; 3) BCR 1,03 dan 
4) PBP 4,94 tahun. Pengolahan biodiesel kemiri sunan sensitif terhadap kenaikan biaya bahan dan penurunan harga biodiesel mencapai 6\% atau lebih. Perubahan pada kisaran persentase tersebut menyebabkan pengolahan biodiesel kemiri sunan tidak layak untuk diusahakan.

Pengembangan unit usaha pada semua lahan tersedia berpotensi menghasilkan biodiesel yang dapat memenuhi 16,68\% kebutuhan solar Jawa Barat. Unit usaha penanaman kemiri sunan maupun pengolahan biodiesel yang dapat dikembangkan masing-masing adalah sebesar 2.365 unit.

\section{B. Saran}

Biodiesel kemiri sunan disarankan dikembangkan di Provinsi Jawa Barat dengan memanfaatkan lahan tersedia secara optimal melalui pelibatan masyarakat dan pelaku usaha serta advis teknis dari akademisi/lembaga litbang. Pemerintah diharapkan dapat berkomitmen untuk memberikan dukungan kelembagaan, insentif dan sarana pendukung. Upaya perbaikan lahan tersedia 2 dan 3 perlu dilakukan agar dapat meningkatkan kelas kesesuaian lahan sehingga dapat meningkatkan peran biodiesel kemiri sunan sebagai bahan bakar alternatif dan mendapatkan manfaat untuk peningkatan kualitas lingkungan.

\section{DAFTAR PUSTAKA}

Aunillah, A. \& D. Pranowo. (2012). Karakteristik biodiesel kemiri sunan (Reutealis trisperma (Blanco) Airy Shaw) menggunakan proses transes-terifikasi dua tahap. Buletin Riset Tanaman Rempah dan Aneka Tanaman Industri, 3(3), 193-200.

Abdulraheem, A., Yahaya, K.A., Muhtar, O.F.E., \& Abogun, S. (2012). Accounting principles of small enterprises in Ilorin Metropolis of Kwara State Nigeria. Research Journal of Finance and Accounting, 3(2),70-77.

Brent, R.J. (2006). Applied benefits-cost analysis ( $2^{\text {nd }}$ Ed.). USA: Edward Elgar Publishing Inc.

Diaz, A.N., Cerqueira, M.B.R., Moura, R.R., Kurz, M.H.S., Clementin, R.M., D'Oca, M.G.M., \& Primel, E.G. (2012). Optimization of a method for the simultaneous determination of glycerides, free and total glycerol in biodiesel ethyl esters from castor oil using gas chromatography. Fuel, 94, 178-183.

Domac, J., Richards, K., \& Risovic, S. (2005). Socio-economic drivers in implementing bioenergy project. Bio-mass and Bioenergy, 28, 97-106.

Faria, R.P.V., Pereira, C.S.M., Silva, V.M.T.M., Loureiro, J.M., \& Rodrigues, A.E. (2013). Glycerol valorisation as biofuels: selection of a suitable solvent for an innovative process for the synthesis of GEA. Chemical Engineering Journal, 233, 159-167.

Hardjowigeno, S. \& Widiatmaka. (2007). Evaluasi kesesuaian lahan \& perencanaan tata guna lahan. Yogyakarta (ID): Gadjah Mada University Press.

Hasegawa, T., Nomura, N., Moriya, T., Nishikawa, H., Yamaguchi, S., \& Kishida, H. (2014). Synthesis of racemic lactide using glycerol by-product from biodiesel fuel production process as feedstock. Energy Procedia, 56, 195-200.

Herman, M., \& Pranowo, D. (2011). Kemiri minyak sebagai tanaman konservasi dan sumber energi terbarukan. Bogor: Balai Penelitian Tanaman Rempah dan Aneka Tanaman Industri.

Herman, M., Syakir, M., Pranowo, D., Saefudin, \& Sumanto. (2013). Kemiri sunan (Reutealis trisperma (Blanco) Airy Shaw) tanaman penghasil minyak nabati dan konservasi lahan. Jakarta (ID): IAARD Pr.

Heryana, N., Usman, \& Rusli. (2009). Proses pembuatan pupuk organik dari bungkil. In Daras, U., Syafaruddin, Ajijah, N., Ferry, Y., Indriati, G., Hasibuan, A.M., ..., \& Rivai, A.M. (Eds.), Kemiri sunan penghasil biodiesel solusi masalah energi masa depan. Bogor (ID): Balai Penelitian Tanaman Rempah dan Aneka Tanaman Industri.

Khotimah, K., Susanto, S.A., Maleha, \& Hani, E.S. (2002). Evaluasi proyek dan perencanaan usaha. Jakarta (ID): Ghalia Indonesia-UMM Press.

Listyati, D. (2009). Biaya produksi pembuatan biodiesel. In Daras, U., Syafaruddin, Ajijah, N., Ferry, Y., Indriati, G., Hasibuan, A.M., 
..., \& Rivai, A.M. (Eds.), Kemiri sunan penghasil biodiesel - solusi masalah energi masa depan. Bogor (ID): Balai Penelitian Tanaman Rempah dan Aneka Tanaman Industri.

Pranowo, D. (2009). Teknologi pembenihan. In Daras, U., Syafaruddin, Ajijah, N., Ferry, Y., Indriati, G., Hasibuan, A.M., ..., \& Rivai, A.M. (Eds.), Kemiri sunan penghasil biodiesel solusi masalah energi masa depan. Bogor (ID): Balai Penelitian Tanaman Rempah dan Aneka Tanaman Industri.

Pranowo, D., Syakir, M., Prastowo, B., Herman, M., Aunillah, A., \& Sumanto. (2013). Pembuatan biodiesel dari kemiri sunan (Reutealis trisperma (Blanco) Airy Shaw) dan pemanfaatan hasil samping. Jakarta (ID): IAARD Pr.

Sanusi, B. (2000). Pengantar evaluasi proyek. Jakarta (ID): Lembaga Penerbit Fakultas Ekonomi Universitas Indonesia.

Supriadi, H., Sasmita, K.D., \& Usman. (2009). Tinjauan agroklimat wilayah pengembangan di Jawa Barat. In Daras, U., Syafaruddin, Ajijah, N., Ferry, Y., Indriati, G., Hasibuan, A.M.,..., \& Rivai, A.M. (Eds.), Kemiri sunan penghasil biodiesel - solusi masalah energi masa depan. Bogor (ID): Balai Penelitian Tanaman Rempah dan Aneka Tanaman Industri.

Vossen, H.A.M. \& Umali, B.E. (2002). Plant resources of South-East Asia (14). Bogor (ID): Prosea Foundation.

Wahyudi, A., Ferry, Y., Herman, M., Pranowo, D., \& Ardana, K. (2009). Proyeksi produksi biodiesel. In Daras, U., Syafaruddin, Ajijah, N., Ferry, Y., Indriati, G., Hasibuan, A.M., ..., \& Rivai, A.M. (Eds.), Kemiri sunan penghasil biodiesel solusi masalah energi masa depan. Bogor (ID): Balai Penelitian Tanaman Rempah dan Aneka Tanaman Industri.

Wulandari, W.S., Darusman, D., Kusmana, C., \& Widiatmaka. (2014). Land suitability analysis of biodiesel crop kemiri sunan (Reutealis trisperma (Blanco) Airy Shaw) in the Province of West Java, Indonesia. Journal of Environment and Earth Science, 4(21), 27-37.

Yang, J., Chen, W., Chen, B., \& Jia, Y. (2012). Economic feasibiility analysis of a renewable energy project in the rural China. Procedia Environmental Sciences, 13, 2280-2283. 